\title{
PEMODELAN INVERSI 2-D MENGGUNAKAN DATA MAGNETOTELLURIK DAERAH PANAS BUMI WAY SELABUNG, KABUPATEN OGAN KOMERING ULU SELATAN, PROVINSI SUMATERA SELATAN
}

\author{
2-D INVERSION MODELING USING MAGNETOTELLURIC DATA \\ AT WAY SELABUNG GEOTHERMAL AREA, \\ SOUTH OGAN KOMERING ULU REGENCY, SOUTH SUMATERA PROVINCE
}

\author{
Irpan IImi ${ }^{1}$, Ildrem Syafri ${ }^{1}$, Agus Didit Haryanto ${ }^{1}$, dan Ahmad Zarkasyi ${ }^{2}$ \\ ${ }^{1}$ Program Pascasarjana, Fakultas Teknik Geologi Universitas Padjadjaran \\ ${ }^{2}$ Pusat Sumber Daya Mineral, Batubara dan Panas Bumi \\ Irpan18002@mail.unpad.ac.id
}

\begin{abstract}
ABSTRAK
Salah satu sifat fisika batuan yang dapat digunakan untuk menganalisis suatu sistem panas bumi adalah tahanan jenis batuan. Metode magnetotellurik merupakan salah satu metode yang dapat digunakan untuk menentukan nilai tahanan jenis batuan. Pengukuran MT dilakukan pada 30 titik ukur dengan lintasan berarah utara-selatan dan jarak antar titik ukur sekitar 2000 meter. Penelitian ini bertujuan untuk melakukan pemodelan inversi 2-D dalam menentukan letak, delineasi, dan kedalaman sistem panas bumi Way Selabung. Berdasarkan hasil analisis data MT dan pemodelan 2-D inversi, sistem panas bumi Way Selabung berada pada zona struktur graben. Munculnya beberapa manifestasi air panas Way Selabung, Lubuk Suban dan Selabung Damping, terbentuk akibat perpotongan Sesar Way Selabung, Sesar Kotadalam dan Sesar Akarjangkang dalam suatu pola hidrogeologi di zona outflow. Hasil pemodelan 2-D memperlihatkan bagian atas terdapat kelompok nilai tahanan jenis rendah $<10$ Ohm.m dengan ketebalan sekitar 1500 meter dari permukaan yang diinterpretasikan sebagai batuan penudung. Di bagian bawahnya terdapat kelompok nilai tahanan jenis sekitar 30-100 Ohm.m dengan kedalaman 1500 meter hingga 1750 meter yang diinterpretasikan sebagai zona reservoir.
\end{abstract}

Kata kunci: Panas Bumi, Way Selabung, Sumatera, Magnetotellurik, inversi 2-D

\section{ABSTRACT}

One of the physical properties of rocks that can be used to analyze a geothermal system is the resistivity of rock. Magnetotelluric method is one method that can be used to determine the resistivity of rock. MT measurements are carried out at 30 measuring points with north-south directed paths and the distance between measuring points is around 2000 meters. This research aims to do 2-D inversion modeling in determining location, delineation, and depth of the geothermal potential of Way Selabung. Based on the results of MT data analysis and 2-D inversion modeling, the Way Selabung geothermal system is in the graben structure zone. The manifestation of Way Selabung, Lubuk Suban and Selabung Damping hot water manifestations is formed due to intersection of Way Selabung, Kotadalam and Akarjangkang faults in a hydrogeological pattern in the outflow zone. 2-D modeling results show the top there is a group of low resistivity value $<10$ Ohm.m with a thickness of about 1500 meters from the surface which is interpreted as caprock. At the bottom there is a group of resistivity values of around 30-100 Ohm.m with a depth of 1500 meters to 1750 meters which is interpreted as a reservoir zone.

Keywords: Geothermal, Way Selabung, Sumatra, Magnetotelluric, 2-D inversion 


\section{MAKALAH ILMIAH}

\section{PENDAHULUAN}

Secara administratif daerah panas bumi Way Selabung berada di Kabupaten Ogan Komering Ulu Selatan, Provinsi Sumatera Selatan (Gambar 1). Sistem panas bumi Way Selabung berada di sebelah utara Danau Ranau dan Gunung Seminung yang di bagian baratnya didominasi oleh batuan vulkanik (andesit-basalt) yang membentuk kaldera dan kawah serta di bagian tengahnya terdapat depresi Kepayang (Simarmata dan Munandar, 2014). Indikasi panas bumi dicirikan dengan munculnya beberapa air panas dengan temperatur antara $40^{\circ} \mathrm{C}$ hingga $93^{\circ} \mathrm{C}$ (Rahadinata dkk., 2014).

Beberapa manifestasi air panas di daerah Way Selabung seperti mata air panas Way Selabung, Lubuk Suban dan Selabung Damping dikontrol oleh struktur Sesar Way Selabung, Sesar Akarjangkang dan Sesar Kotadalam, yang menjadikan daerah tersebut sebagai zona permeabel yang meloloskan aliran air panas dari kedalaman (Simarmata dan Munandar, 2014). Penelitian ini bertujuan untuk melakukan pemodelan resistivitas 2-D menggunakan data MT serta menegaskan keprospekan potensi panas bumi (letak, delineasi, dan kedalaman) di Way Selabung.

\section{METODOLOGI}

\section{Metode Magnetotellurik (MT)}

Metode magnetotellurik (MT) adalah metode elektromagnetik (EM) pasif yang mengukur fluktuasi medan listrik dan medan magnet alam dengan arah orthogonal di permukaan bumi sebagai cara untuk menghitung konduktivitas struktur bumi dalam rentang kedalaman beberapa puluh meter sampai ratusan kilometer (Simpson dan Bahr, 2005). Sumber medan EM frekuensi tinggi $(>1 \mathrm{~Hz})$ berasal dari kegiatan Guntur dan kilat yang terjadi dalam lapisan atmosfer bumi secara menyeluruh. Sumber medan EM frekuensi rendah $(<1$ $\mathrm{Hz}$ ) berasal dari gelombang micro (micropulsation) karena interaksi antara partikel matahari (solar wind) dengan medan magnet bumi (Grandis, 2010). Tahanan jenis atau resistivitas diperoleh dari perbandingan besarnya medan listrik dan medan magnet yang dikenal dengan persamaan Cagniard (Cagniard, 1953). Persamaan ini dihasilkan dari persamaan Maxwell dengan asumsi gelombang bidang.

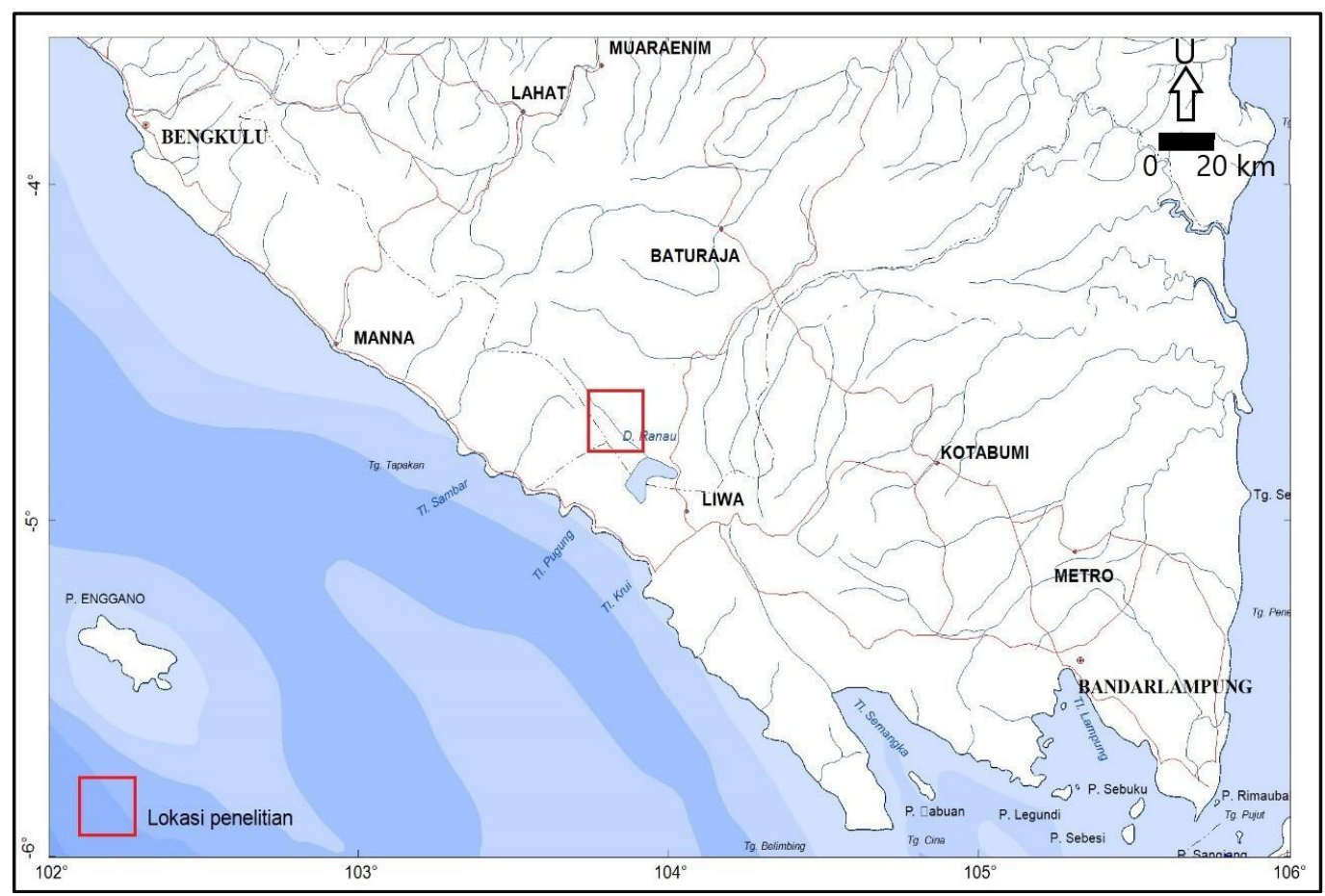

Gambar 1. Peta lokasi daerah penelitian 


$$
\rho_{\alpha}=\frac{1}{5} \mathrm{f} x\left|\frac{\mathrm{E}}{\mathrm{H}}\right|^{2}
$$

dengan $\rho \alpha$ merupakan tahanan jenis semu (Ohm-m), $f$ adalah frekuensi $(\mathrm{Hz}), \mathrm{E}$ adalah besarnya medan listrik $(\mathrm{mV} / \mathrm{km})$, dan $\mathrm{H}$ adalah besarnya medan magnet (nT).

Amplitudo gelombang EM mengalami atenuasi secara eksponensial terhadap kedalaman ketika melewati lapisan konduktif. Untuk dapat memperkirakan kedalaman penetrasi atau kedalaman investigasi gelombang EM dapat digunakan besaran skin depth yang didefinisikan sebagai kedalaman pada suatu medium homogen dimana amplitude gelombang EM telah tereduksi menjadi $1 / \mathrm{e}$ dari amplitudonya di permukaan bumi (Grandis, 2013). Nilai skin depth dipengaruhi oleh tahanan jenis batuan dan frekuensi yang digunakan dan dirumuskan sebagai berikut:

$$
\delta=503 \sqrt{\frac{\rho_{a}}{f}}
$$

dengan $f$ merupakan frekuensi gelombang elektromagnetik $(\mathrm{Hz}), \boldsymbol{\delta}$ adalah skin depth (m) dan $\rho_{\alpha}$ adalah tahanan jenis medium homogen ( Ohm $\mathrm{m}$ ). Besaran skin depth digunakan untuk memperkirakan kedalaman penetrasi atau kedalaman investigasi gelombang EM. Semakin tinggi frekuensi alat yang digunakan maka akan semakin dangkal penetrasinya. Sebaliknya, semakin rendah frekuensi alat yang digunakan, maka semakin dalam pula penetrasi yang didapatkan.

\section{Inversi 2-D}

Proses pemodelan inversi data MT diperlukan dalam rangka menggambarkan distribusi nilai tahanan jenis bawah permukaan. Pemodelan inversi ini sering pula disebut sebagai data fitting karena dalam prosesnya dicari parameter model yang menghasilkan respons yang fit dengan data pengamatan (Takodama dkk., 2018). Model yang dihasilkan dari proses pemodelan inversi bersifat tidak unik. Ketidak-unikan (nonuniqueness) solusi pemodelan geofisika adalah akibat dari paling tidak tiga hal utama, yaitu: sifat fisika fenomena yang ditinjau, adanya kesalahan atau bising (noise) pada data dan kekurangan data dalam membatasi atau mendefiniskan (menjadi constrain) solusi (Grandis, 2009).

Pemodelan inversi 2-D merupakan salah satu proses pengolahan data lapangan yang melibatkan teknik penyelesaian matematika dan statistik untuk memperoleh distribusi sifat fisis batuan di bawah permukaan (Qahhar dkk., 2015). Pemodelan 2-D menggunakan perangkat lunak WinGLink versi 2.21.03. Pemodelan ini menggunakan algoritma NLCG (Nonlinear Conjugate Gradients) yang dapat secara langsung meminimalisasi problem yang bukan kuadratik, membebaskan kerangka iterasi dan inversi linear (Rodi dan Mackie, 2001). Metode ini mengevaluasi fungsi forward untuk setiap model terbaru. Oleh karena itu, setiap satu kali iterasi pada inversi untuk setiap lintasan menyelesaikan dua atau tiga problem forward (Siripunvaraporn, 2012).

\section{Akusisi Data}

Data yang digunakan pada penelitian ini merupakan data yang dimiliki oleh Pusat Sumber Daya Mineral, Batubara dan Panas Bumi (PSDMBP). Tahap pengambilan data primer di daerah panas bumi Way Selabung dilakukan oleh Tim Penyelidikan Pusat Sumber Daya Geologi TA 2011 yang melakukan pengukuran MT sebanyak 30 titik ukur. Data magnetotellurik yang terukur merupakan data dalam domain waktu (time series). Lokasi survei magnetotellurik berada di kawasan Way Selabung, Kecamatan Mekakau Ilir, Kabupaten Ogan Komering Ulu Selatan, Provinsi Sumatera Selatan. Pengukuran data MT menggunakan alat MTU-5A produk dari Phoenix Geophysics, Kanada (Gambar 2). 


\section{MAKALAH ILMIAH}

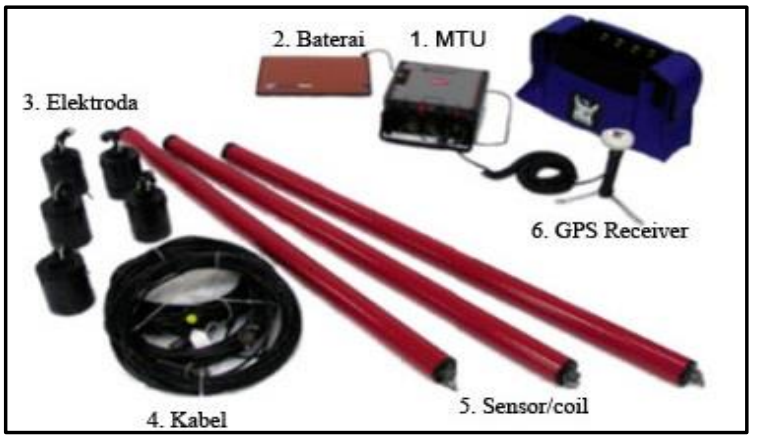

Gambar 2. Alat-alat yang digunakan dalam pengukuran MT (Phoenix Geophysics, 2007)

Pengukuran MT di daerah ini membentuk lintasan berarah utara-selatan dengan jarak antar titik ukur sekitar 2000 meter (Gambar 3). Sebaran titik ukur ini dirancang sedemikian rupa agar dapat melingkupi seluruh daerah prospek. Pengukuran MT ini dilakukan dari siang/sore hari hingga pagi hari dengan selang waktu antara 13 jam sampai dengan 17 jam, dengan harapan pada waktu tersebut gangguan selama pengukuran akan lebih kecil. Walaupun sebaran titik ukur cenderung membentuk lintasan berarah utara-selatan, tetapi pada saat melakukan pemodelan lintasan (penampang model 2-D) ditarik berarah baratdaya-timurlaut $\left(\mathrm{N} 45^{\circ} \mathrm{E}\right)$ supaya tegak lurus dengan struktur utama yang berarah baratlaut-tenggara.

\section{Pengolahan Data}

Sebelum dilakukan pemodelan, data terlebih dahulu diproses melalui tahapan penyeleksian data time series. Proses pra pengolahan ini menggunakan program Synchro Time Series Viewer. Data time series MT yang diperoleh pada masingmasing stasiun, diproses menggunakan statistically robust algorithms (Jones dkk., 1989), dan dilanjutkan pada MT Editor untuk penyeleksian crosspower. Pada proses ini rentang frekuensi data magnetotelurik yang diambil mulai dari $320 \mathrm{~Hz}$ hingga $0,01 \mathrm{~Hz}$.

Pada saat melakukan pemodelan, data MT dirotasi terlebih dahulu. Penentuan arah rotasi berdasarkan analisis data tipper strike (Gambar 4) dan sebaran nilai tahanan jenis ataupun Anomali Bouguer, struktur utama yang berkembang di daerah ini cenderung berarah hampir baratlaut-tenggara. Hasil analisis, data MT dirotasi terlebih dahulu ke arah $45^{\circ}$ karena itu agar data TE maupun TM lebih menggambarkan keadaan bawah permukaan yang sebenarnya. Setelah melalui editing data rotasi dan koreksi statik, kemudian dilanjutkan dengan pemodelan melalui teknik Inversi data 2-Dimensi menggunakan software WinGlink (Zarkasyi dan Wahyuningsih, 2018).

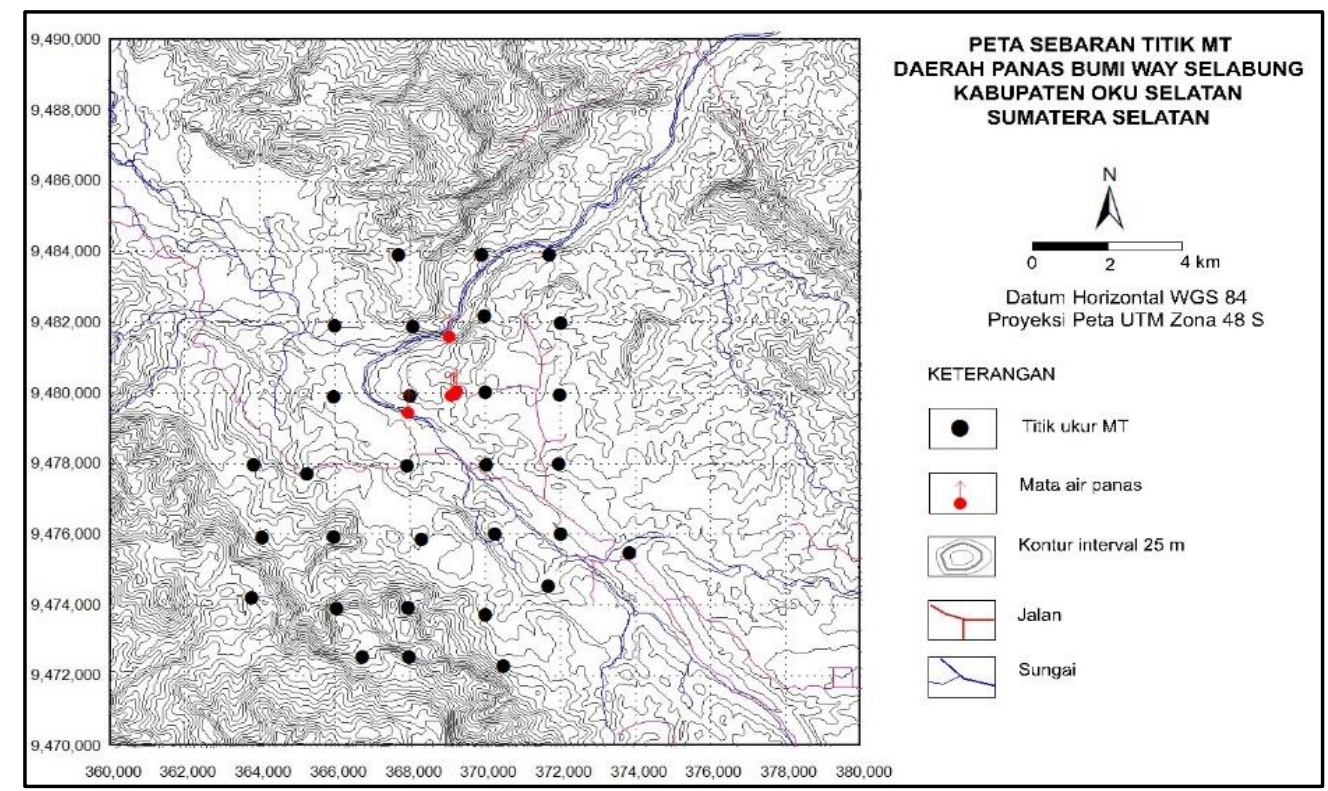

Gambar 3. Peta sebaran titik magnetotellurik daerah panas bumi Way Selabung (Sugianto, 2011) 


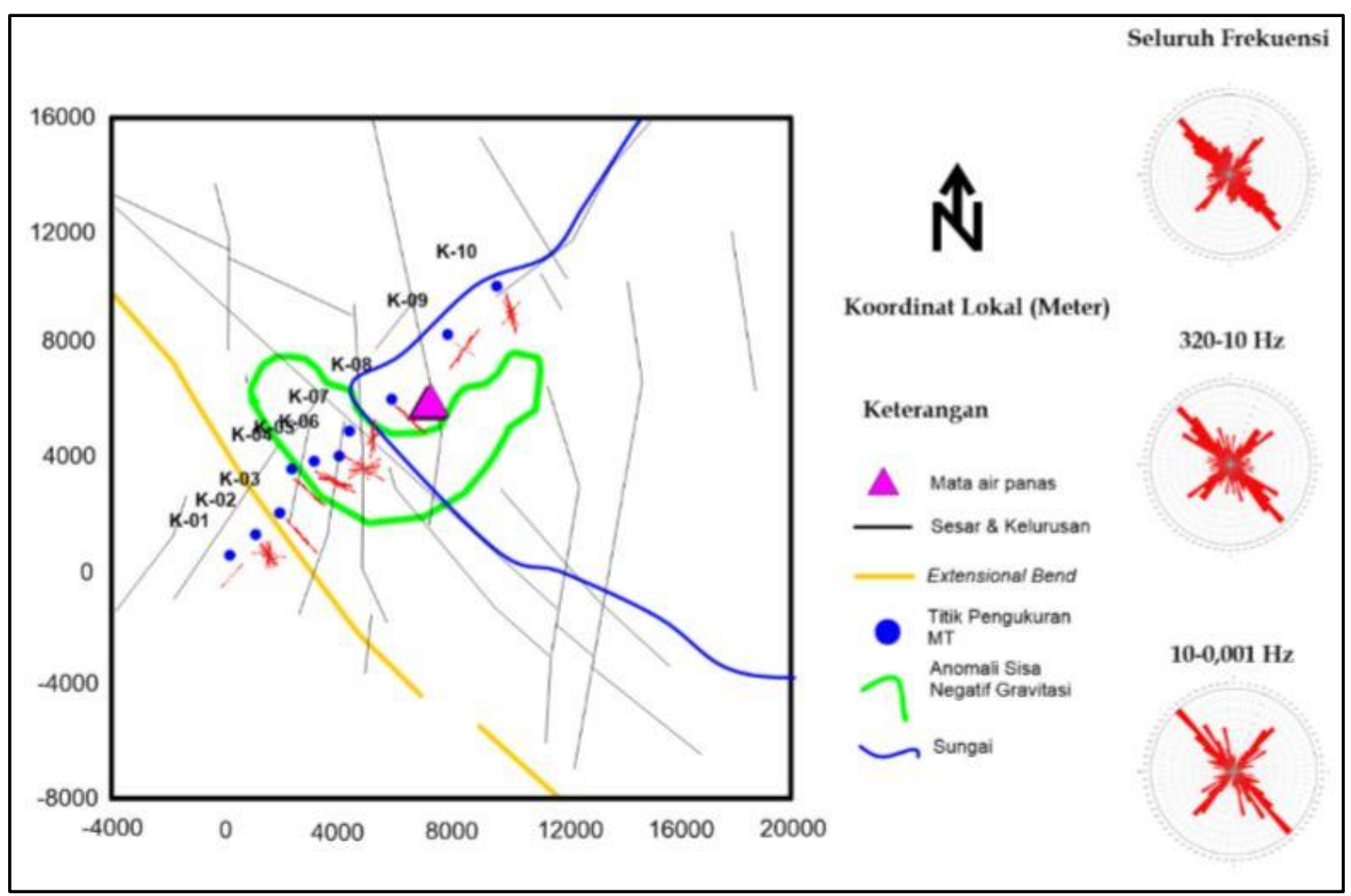

Gambar 4. Peta hasil plot rose diagram tipper strike (Baskoro, 2016)

\section{GEOLOGI}

Secara umum struktur Pulau Sumatera di bagi menjadi tiga bagian yaitu: zona busur depan, jalur pegunungan barisan dan Sesar Semangko, serta cekungan belakang busur (Barber dkk., 2005). Berdasarkan posisi geografisnya daerah penelitian berada pada jalur pegunungan barisan dan sesar Semangko. Jalur Pegunungan Barisan tersusun oleh batuan dasar Paleozoikum Akhir dan batuan sedimen Mesozoikum, batuan gunungapi, batuan metamorf, deformasi batuan dan intrusi granit, kemudian di atasnya terdapat batuan sedimen dan produk vulkanik Kenozoikum termasuk juga sistem subduksi resen yang membentuk jajaran gunungapi aktif.

Sesar Semangko memiliki pergerakan mendatar menganan yang bekerja sepanjang Pulau Sumatera dan melalui Jalur Pegunungan Barisan berarah baratlaut-tenggara menghasilkan zona kompresi dan ekstensi yang membentuk area pengangkatan dan pull apart basin yang membentuk graben sepanjang garis sistem sesar.
Area penelitian berada di sebelah utara Danau Ranau yang didominasi oleh batuan vulkanik dan batuan sedimen klastik yang berumur Tersier hingga Kuarter. Batuan termuda yang diperoleh dari analisis umur batuan dengan metode jejak belah adalah lava basalt produk Tebat Gayat diperoleh kisaran umur 0,4 \pm 0,2 juta tahun yang lalu atau Kala Plistosen (Nurhadi dkk., 2011).

Batuan-batuan yang mendominasi daerah penelitian merupakan bagian dari Formasi Ranau (Qtr) yang terdiri dari tuf kristalin, tuf batuapung, tuf dengan sisipan batulempung karbonatan dan Satuan Batugunungapi (Qv) yang terdiri dari lava, tuf dan breksi gunungapi bersusunan andesit-basal dari batuan vulkanik Jambul dan Pandan (Kusnadi, 2011) (Gambar 5). Stratigrafi batuan terdiri dari Satuan Lava Akar Jangkang, Batupasir, Lava Asadimana, Lava Pematang Gong, Breksi Tua, Aliran Piroklastik Ranau, Aliran Piroklastik Sapatuhu, Jatuhan Piroklastik Ranau, Lava Laai, Lava Bengkok, Lava Pandan, Lava Gedang, Lava Perean, Lava Tebat Gayat, dan endapan Aluvium (Gambar 6). 


\section{MAKALAH ILMIAH}

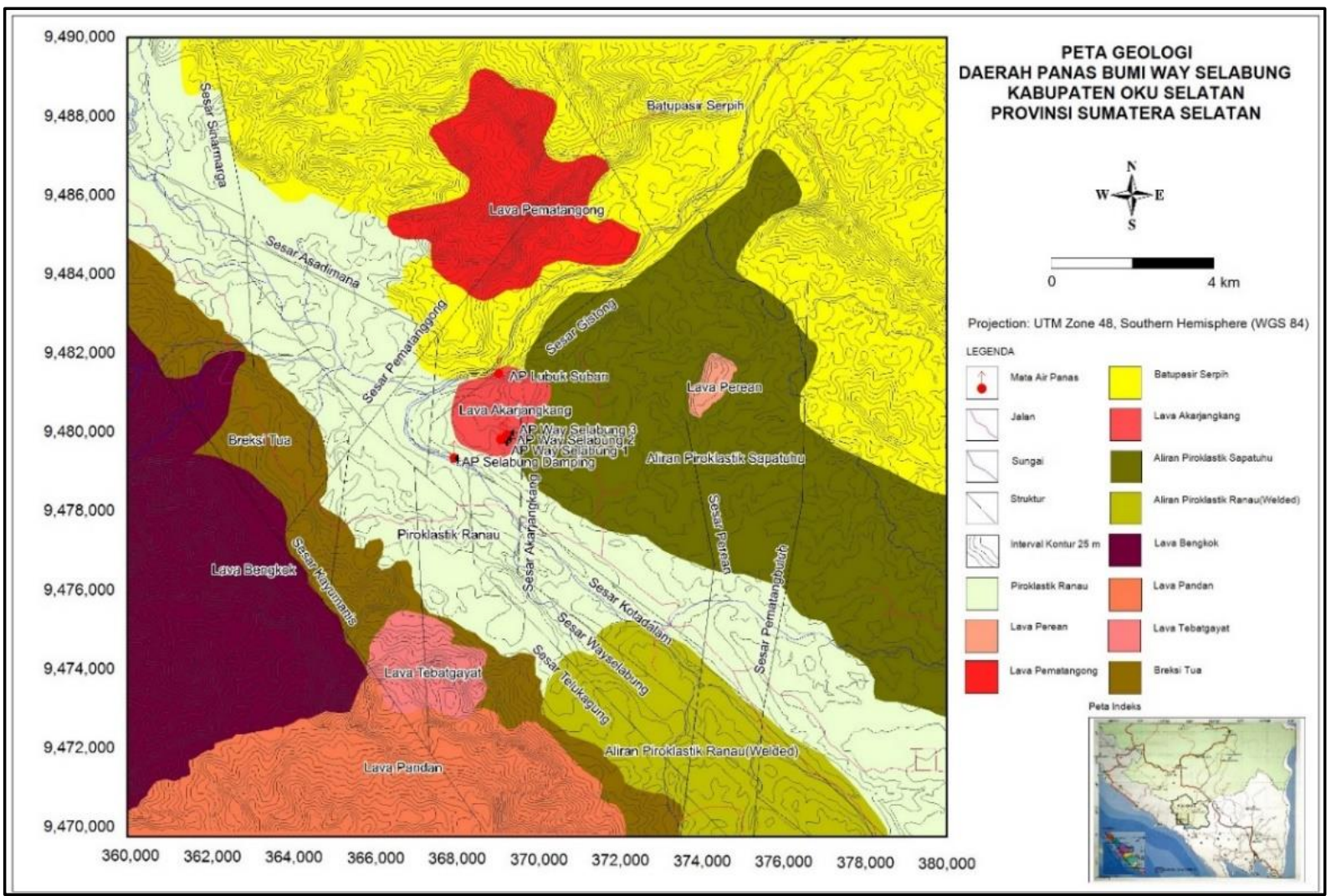

Gambar 5. Peta Geologi daerah panas bumi Way Selabung (modifikasi dari Nurhadi dkk., 2011)

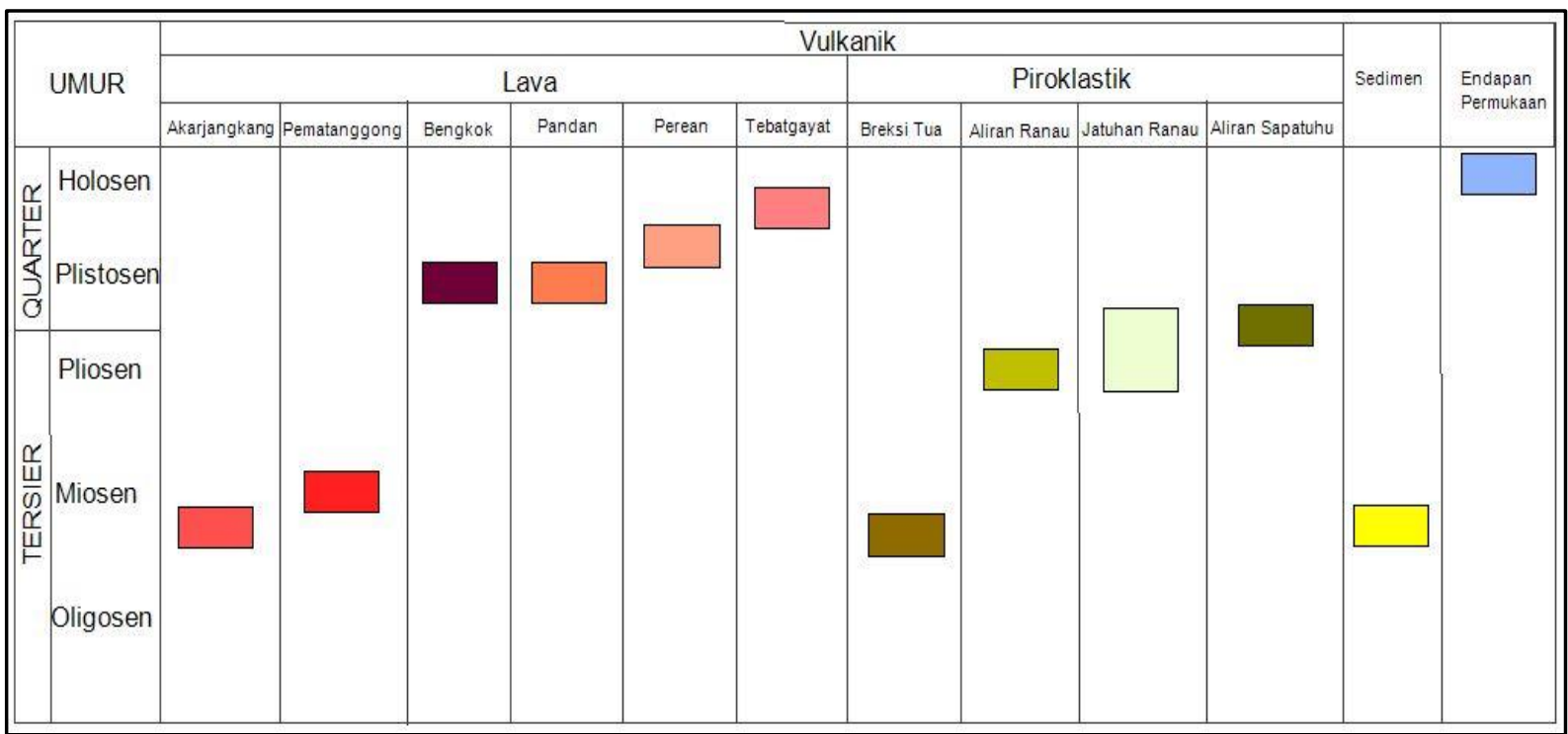

Gambar 6. Stratigrafi batuan area penelitian (Nurhadi dkk., 2011)

\section{HASIL DAN PEMBAHASAN}

Peta sebaran tahanan jenis semu invarian merupakan kombinasi kurva data observasi dari pengukuran MT. Pada frekuensi tinggi (100 Hz dan $10 \mathrm{~Hz}$ ) anomali - anomali nilai tahanan jenis rendah $<10$ Ohm-m menempati di bagian barat area penelitian merupakan respon dari batuan caprock sedangkan tahanan jenis rendah di bagian timurlaut merupakan respon dari batuan sedimen (Gambar 7). 
Pada peta tahanan jenis perkedalaman nilai tahanan jenis rendah $<10$ Ohm-m menempati di bagian barat area penelitian yang luas areanya semakin mengecil pada kedalaman $750 \mathrm{~m}$. Lapisan batuan bertahanan jenis rendah tersebut diperkirakan merupakan respon dari batuan yang teralterasi akibat fluida hidrotermal dan berperan sebagai lapisan penudung (caprock) (Gambar 8).

Nilai tahanan jenis tinggi mulai terlihat pada kedalaman $1500 \mathrm{~m}$ dan makin meluas pada kedalaman $2000 \mathrm{~m}$ dengan arah liniasi kontur baratdaya-timurlaut yang merupakan respon dari struktur sekunder Sesar Semangko yang mengakibatkan munculnya mata air panas Way Selabung.

Berdasarkan hasil analisis data MT dan pemodelan 2-D inversi, area prospek panas bumi berada di bagian Baratdaya area penelitian. Terdapat 4 penampang lintasan 2-D yang memotong area prospek dapat dilihat pada Gambar 9. Pada penampang 3 terdapat nilai tahanan jenis rendah pada bagian baratdaya yang diperkirakan sebagai lapisan batuan caprock yang memiliki ketebalan 1250 meter dari permukaan. Sedangkan zona puncak reservoir diduga berkisar pada kedalaman 1250 meter hingga 1500 meter. Di bagian timurlaut terdapat nilai tahanan jenis tinggi yang menerus ke permukaan diperkirakan sebagai batuan Lava Akarjangkang, perpotongan Sesar Akarjangkang dengan Sesar Gistong sebagai jalan keluarnya mata air panas Lubuk Suban.

Pada penampang 4 di bagian Baratdaya terdapat nilai tahanan jenis tinggi yang diperkirakan sebagai batuan Lava Bengkok dan Sesar Kayumanis. Lapisan caprock memiliki ketebalan 1250 meter dari permukaan dan puncak reservoir pada kedalaman 1250 meter hingga 1500 meter. Di bagian timurlaut terdapat nilai tahanan jenis tinggi yang menerus ke permukaan diperkirakan sebagai batuan Lava Akarjangkang yang menghasilkan Sesar Akarjangkang sebagai jalan keluarnya mata air panas Way Selabung.

Pada penampang 5 lapisan caprock mengalami penebalan sampai kedalaman 1500 meter dan posisi puncak reservoir pada kedalaman 1500 meter hingga 1750 meter. Pada penampang ini nilai tahanan jenis tinggi mengapit nilai tahanan jenis sedang yang diinterpretasikan sebagai respon dari struktur graben dari Sesar Semangko.

Semakin ke arah tenggara area prospek lapisan caprock dan puncak reservoir semakin dalam. Terlihat pada penampang 6 lapisan caprock memiliki ketebalan 1750 meter dari permukaan. Sedangkan zona puncak reservoir berkisar pada kedalaman 1750 meter hingga 2000 meter. Pada penampang ini struktur graben semakin terlihat jelas di bagian baratdaya-timurlaut terjadi pengapitan nilai tahanan jenis sedang oleh tahanan jenis tinggi.

Pada Gambar 10 konseptual model panas bumi Way Selabung memperlihatkan bahwa area prospek berada pada zona struktur graben yang diapit oleh Sesar Kayumanis dan Sesar Akarjangkang.

Batuan Piroklastik Ranau yang mengalami alterasi akibat proses hidrotermal adalah lapisan caprock yang diperkirakan memiliki ketebalan \pm 1500 meter dari permukaan. Sedangkan puncak reservoir diperkirakan berada pada kedalaman \pm 1500 meter hingga \pm 1750 meter.

Keberadaan manifestasi air panas Way Selabung, Selabung Damping dan Lubuk Suban di sekitar batuan lava Akarjangkang berhubungan dengan keberadaan kelompok sesar di sekitar Lava Akarjangkang sebagai jalan keluarnya air panas. 


\section{MAKALAH ILMIAH}

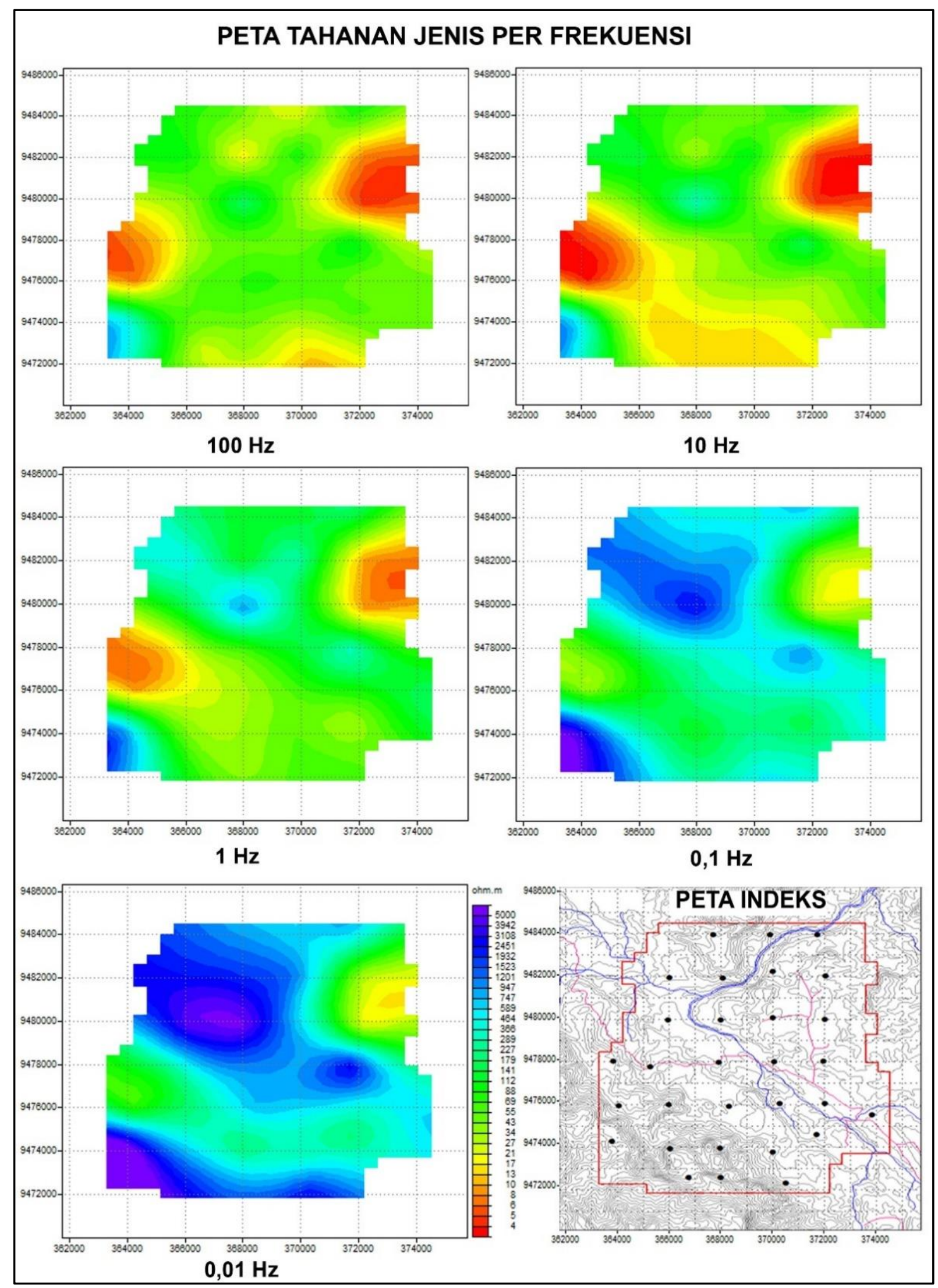

Gambar 7. Peta tahanan jenis per frekuensi $(100-0,01 \mathrm{~Hz})$ 


\section{MAKALAH ILMIAH}

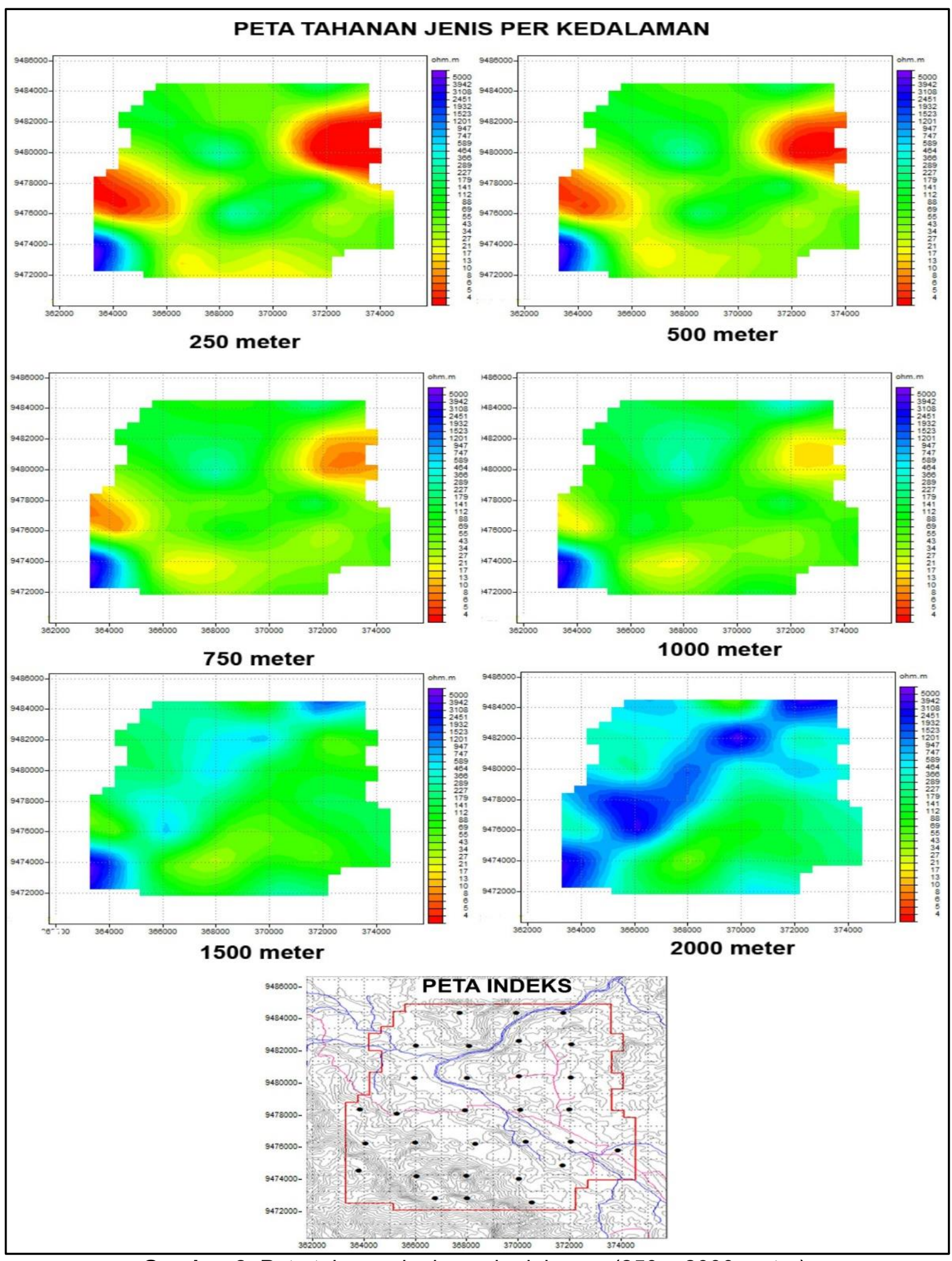

Gambar 8. Peta tahanan jenis per kedalaman (250 - 2000 meter) 


\section{MAKALAH ILMIAH}

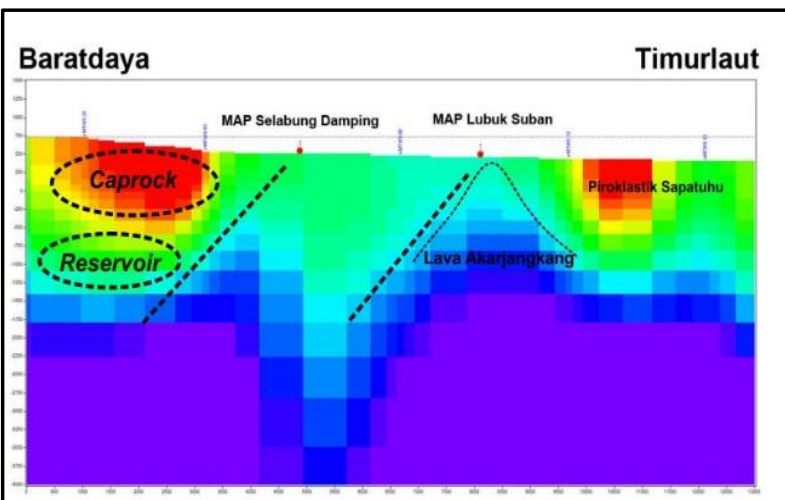

Penampang Line 3

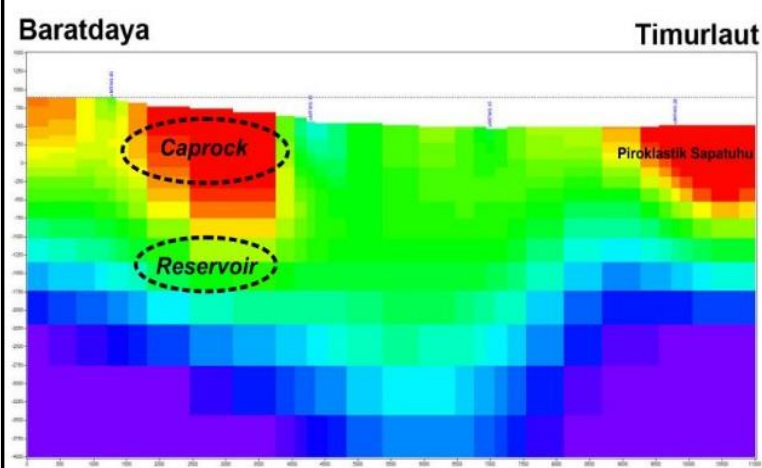

\section{Penampang Line 5}

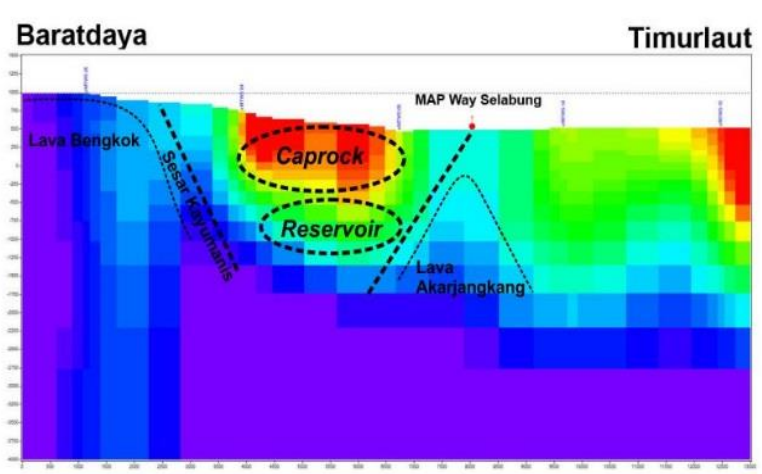

Penampang Line 4
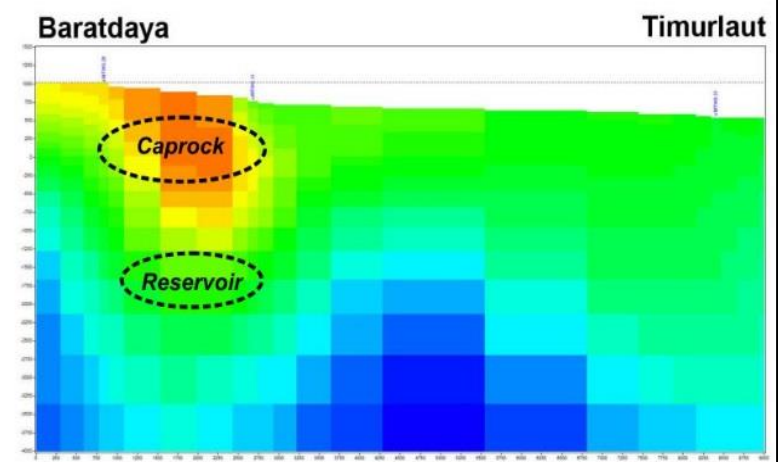

Penampang Line 6

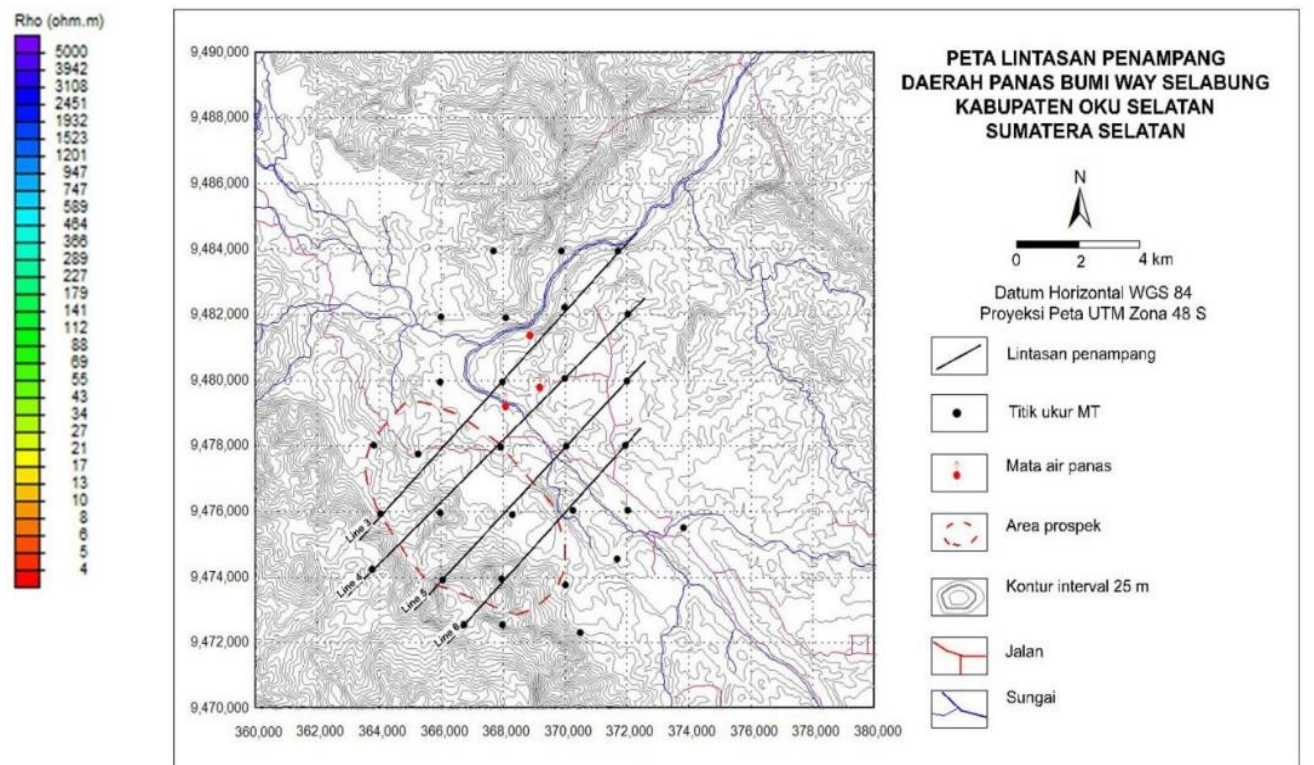

Gambar 9. Penampang tahanan jenis hasil pemodelan 2-D 


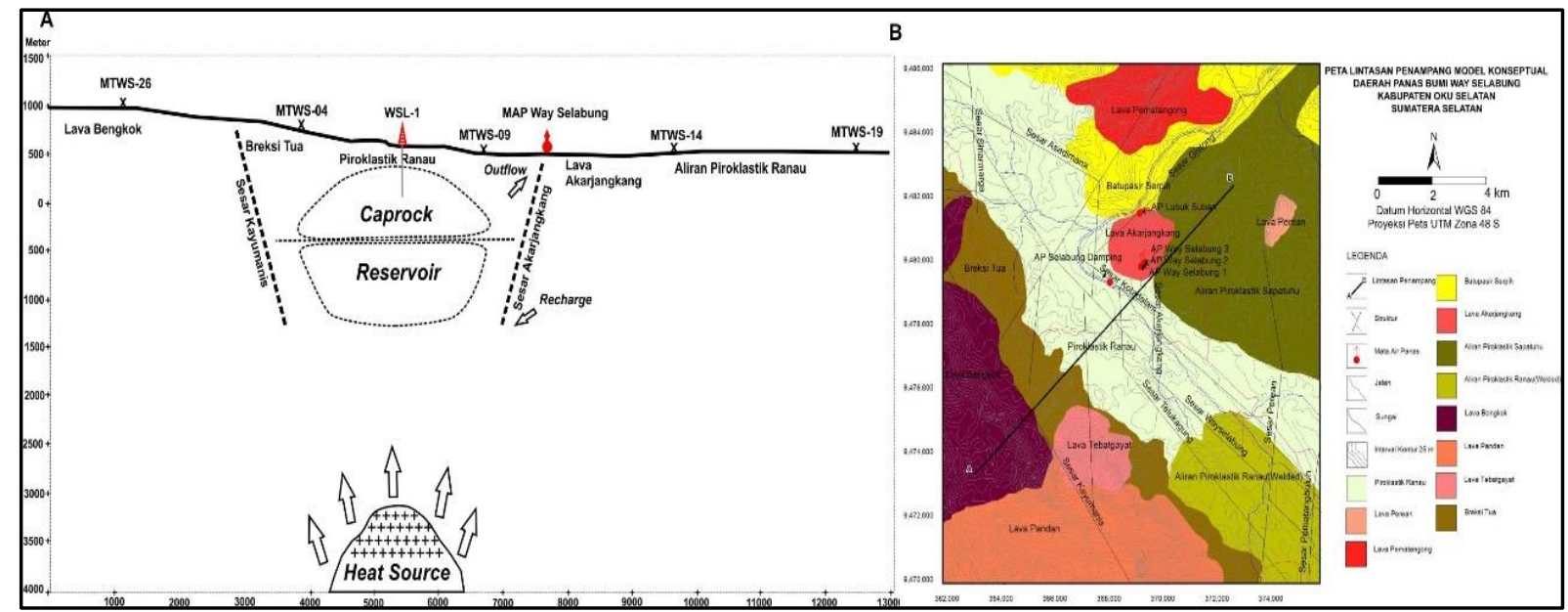

Gambar 10. Model konseptual panas bumi Way Selabung menggunakan lintasan penampang 4

\section{KESIMPULAN}

Berdasarkan hasil analisis data MT dan pemodelan 2-D inversi, sistem panas bumi di daerah Way Selabung berada pada zona struktur graben yang berhubungan dengan munculnya manifestasi air panas Way Selabung, Lubuk Suban dan Selabung Damping di sekitar Lava Akarjangkang dengan permeabilitas yang terbentuk akibat perpotongan Sesar Way Selabung, Sesar Kotadalam dan Sesar Akarjangkang dalam suatu pola hidrogeologi di zona outflow. Berdasarkan posisi sistem panas bumi Way Selabung berada pada zona struktur graben dan berdasarkan temperatur reservoirnya maka reservoir panas bumi Way Selabung merupakan reservoir compressed liquid. Puncak reservoir berada pada kedalaman \pm 1500 meter hingga \pm 1750 meter sedangkan ketebalan lapisan caprock diperkirakan \pm 1500 meter dari permukaan. Berdasarkan hasil korelasi dengan data geologi, lapisan caprock merupakan batuan vulkanik yang mengalami alterasi sedangkan reservoir merupakan batuan sedimen dan lava tua yang terkekarkan.

\section{UCAPAN TERIMA KASIH}

Penulis mengucapkan terima kasih kepada Dikdik Risdianto, S.T., M.T. sebagai Kepala Subbidang Eksplorasi Panas Bumi (PSDMBP) yang telah memberikan izin dalam mengolah data MT ini. Penulis juga mengucapkan terima kasih kepada Tony Rahadinata, S.Si., dan Wiwid Joni, S.Si atas diskusi dan pemberian pengalaman ilmunya. Penulis juga mengucapkan terima kasih kepada semua pihak yang mendukung, membantu, dan memberi kemudahan akses data dalam pembuatan tulisan ini.

\section{DAFTAR PUSTAKA}

Barber, A.J., Crow, M.J., Milsom, J., 2005. Sumatra: Geology, resources and tectonic evolution. Geological Society of London.

Baskoro, Y., 2016. Pemodelan 2-D Magnetotellurik Pada Sistem Panas Bumi Area "Parkir", Kabupaten Oku Selatan, Sumatera Selatan. ETD Universitas Gadjah Mada.

Cagniard, L., 1953. Basic theory of the magneto-telluric method of geophysical prospecting. Geophysics 18, 605-635.

Grandis, H., 2013. Metoda Magnetotellurik (MT). Institut Teknologi Bandung, Bandung.

Grandis, H., 2010. Studi efek statik pada data magnetotellurik menggunakan pemodelan inversi 2-D, in: Prosiding Seminar Nasional Energi.

Grandis, H., 2009. Pengantar pemodelan inversi geofisika. Himpunan Ahli Geofisika Indonesia (HAGI). 


\section{MAKALAH ILMIAH}

Jones, A.G., A. D. Chave, G. Egbert, D. Auld, K. Bahr, 1989. A comparison of techniques for magnetotelluric response function estimation. J. Geophys. Res., 94, 14201-14213. https://doi.org/doi:10.1029/jb094ib10p 14201.

Kusnadi, D., 2011. Laporan Akhir Survei Terpadu Geologi dan Geokimia Daerah Panas Bumi Way Selabung Kabupaten Ogan Kemiring Ulu Selatan, Provinsi Sumatera Selatan. Pusat Sumber Daya Geologi, Bandung.

Nurhadi, M., Munandar, A., Kusnadi, D., Zarkasyi, A., Suryakusuma, D., Sugianto, A., 2011. Survei Terpadu Geologi, Geokimia, dan Geofisika Daerah Panas Bumi Way Selabung, Kabupaten Oku Selatan, Provinsi Sumatera Selatan. Pusat Sumber Daya Geologi.

Phoenix Geophysics, 2007. V5 System 2000 MTU/MTU-A User Guide. Phoenix Geophysics. Phoenix Geophysics.

Rahadinata, T., Sugianto, A., 2014. Survei Magnetotellurik dan TDEM Daerah Panas Bumi Way Selabung, Kabupaten Oku Selatan, Provinsi Sumatera Selatan. PSDG.

Rodi, W., Mackie, R.L., 2001. Nonlinear conjugate gradients algorithm for 2-D magnettotelluric inversion. Geophysics Journal International 66(1):174-187.
Simarmata, R.S., Munandar, A., 2014. Survei Landaian Suhu Sumur WSL-2, in: Prosiding Hasil Kegiatan Sumber Daya Geologi.

Simarmata, R.S.L., Munandar, A., 2014. Survei Landaian Suhu Sumur WSL-1, in: Prosiding Hasil Kegiatan Sumber Daya Geologi. p. 10.

Simpson, F., Bahr, K., 2005. Practical magnetotellurics. University Press.

Siripunvaraporn, W., 2012. Three Dimensional Magnetotelluric Inversion: An Introductory Guide for Developers and Users. SurvGeophys 33:5-27.

Sugianto, A., 2011. Laporan Akhir Survei Magnetotellurik Daerah Panas Bumi Way Selabung Kabupaten Oku Selatan, Sumatera Selatan. Pusat Sumber Daya Geologi, Bandung.

Takodama, I., Zarkasyi, A., Nurhadi, M., Dewi, R., 2018. Identifikasi Sistem Panas Bumi Daerah Wapsalit Berdasarkan Struktur Tahanan Jenis Data Magnetotellurik. Buletin Sumber daya Geologi.

Zarkasyi, A., Wahyuningsih, R., 2018. Pemodelan Reservoir Panas Bumi Daerah Dua Saudara, Kota Bitung, Provinsi Sulawesi Utara, Dengan Menggunakan Inversi 2-D Data Magnetotellurik. Buletin Sumber daya Geologi.

\begin{tabular}{|ll|}
\hline Diterima & $: 9$ April 2020 \\
Direvisi & $: 24$ April 2020 \\
Disetujui & $: 31$ Mei 2020
\end{tabular}

